\title{
Design High Impact Fuzzy Baseline Variable Structure Methodology to Artificial Adjust Fuel Ratio
}

\author{
Farzin Piltan \\ Industrial Electrical and Electronic Engineering SanatkadeheSabze Pasargad. CO (S.S.P. Co), NO:16, PO.Code 71347- \\ 66773, Fourth floor, Dena Apr, Seven Tir Ave, Shiraz, Iran \\ Email: SSP.ROBOTIC@gmail.com
}

Mojdeh Piran

Industrial Electrical and Electronic Engineering SanatkadeheSabze Pasargad. CO (S.S.P. Co), NO:16, PO.Code 7134766773, Fourth floor, Dena Apr , Seven Tir Ave, Shiraz, Iran

Email: SSP.ROBOTIC@yahoo.com

\author{
Mansour Bazregar \\ Industrial Electrical and Electronic Engineering SanatkadeheSabze Pasargad. CO (S.S.P. Co), NO:16, PO.Code 71347- \\ 66773, Fourth floor, Dena Apr , Seven Tir Ave, Shiraz , Iran \\ Email: SSP.ROBOTIC@yahoo.com
}

\author{
Mehdi Akbari \\ Industrial Electrical and Electronic Engineering SanatkadeheSabze Pasargad. CO (S.S.P. Co), NO:16, PO.Code 71347- \\ 66773, Fourth floor, Dena Apr, Seven Tir Ave, Shiraz, Iran \\ Email: SSP.ROBOTIC@yahoo.com
}

\begin{abstract}
This paper expands a Multi Input Multi Output (MIMO) fuzzy baseline variable structure control (VSC) which controller coefficient is off-line tuned by gradient descent algorithm. The main goal is to adjust the optimal value for fuel ratio (FR) in motor engine. The fuzzy inference system in proposed methodology is works based on Mamdani-Lyapunov fuzzy inference system (FIS). To reduce dependence on the gain updating factor coefficients of the fuzzy methodology, PID baseline method is introduced. This new method provides an optimal setting for other factors which crated by PID baseline method. The gradient descent methodology is off-line tune all coefficients of baseline fuzzy and variable structure function based on mathematical optimization methodology. The performance of proposed methodology is validated through comparison with fuzzy variable structure methodology (FVSC). Simulation results signify good performance of fuel ratio in presence of different torque load and external disturbance.
\end{abstract}

Index Terms - Baseline Method, Gradient Descent Optimal Algorithm, Variable Structure Control, Fuzzy Inference System, Lyapunov Based Stability

\section{Introduction}

The internal combustion (IC) engine is designed to produce power from the energy that is contained in its fuel. More specifically, its fuel contains chemical energy and together with air, this mixture is burned to output mechanical power [1-3]. In an internal combustion engine, a piston moves up and down in a cylinder and power is transferred through a connecting rod to a crank shaft. The continual motion of the piston and rotation of the crank shaft as air and fuel enter and exit the cylinder through the intake and exhaust valves is known as an engine cycle. The fuel ratio can be used to determine which fuel system should have a larger impact on how much fuel is injected into the cylinder [4-9]. Since a direct fuel injector (DI) has immediate injection of its fuel with significant charge cooling effect, it can have a quicker response to the desired amount of fuel that is needed by an engine. Although a port fuel injector (PFI) may have a slower response due to its wall-wetting dynamics, the fuel ratio will impact the combustion characteristics of an engine. Fuel ratio also can be used to regulate or control two fuel types. For example, an engine may have the ability to run on gasoline and ethanol. The gasoline could be injected by a PFI, while the ethanol could be injected by a DI [1-9].

Controller is a device which can sense information from linear or nonlinear system (e.g., IC engine) to 
improve the systems performance [10-20]. The main targets in designing control systems are stability, good disturbance rejection, and small tracking error[21-30]. Some of IC engines are controlled by linear PID controllers, but the design of linear controller for IC engine is extremely difficult because this system is hardly nonlinear and uncertain [12, 31-40]. To reduce the above challenges, the nonlinear robust controller is used to control of IC engine. Variable structure methodology (VSC) is a powerful nonlinear robust controller under condition of partly uncertain dynamic parameters of IC engine's dynamic [10-30]. Chattering phenomenon and nonlinear equivalent dynamic formulation in uncertain dynamic parameter are two main drawbacks in VSC [33-39]. The chattering phenomenon problem in VSC is reduced by using linear saturation boundary layer function but proves the stability is very difficult and increases the error. The nonlinear equivalent dynamic formulation problem in uncertain IC engine is solved by using fuzzy logic theorem and applied to VSC [41-55]. To estimate the system dynamics, fuzzy logic method is applied to VSC, but this method has problem to tune the FR. MIMO fuzzy variable structure control with saturation function is a chattering free dynamic model-free controller but this method has two main drawbacks; variable structure slope and error. Pure variable structure methodology and fuzzy variable structure methodology have difficulty in handling variation in torque load. It is possible to solve this problem by combining fuzzy variable structure method and baseline methodology to improve the systems adjust FR by off-line tuning method.

\section{Theory}

\subsection{Dynamic Formulation of IC Engine}

Dynamic modeling of IC engine is used to describe the nonlinear behavior of IC engine, design of model based controller such as pure variable structure controller based on nonlinear dynamic equations, and for simulation. The dynamic modeling describes the relationship between fuel to air ratio to PFI and DI and also it can be used to describe the particular dynamic effects (e.g., motor pressure, angular speed, mass of air in cylinder, and the other parameters) to behavior of system[1].

The equation of an IC engine governed by the following equation $[1,4,25,29,43-44]$ :

$$
\begin{aligned}
& {\left[\begin{array}{c}
\mathrm{PFI} \\
\mathrm{DI}
\end{array}\right]=\left[\begin{array}{ll}
\dot{\mathbf{M}}_{\text {air } 11} & \dot{\mathbf{M}}_{\text {air }} \\
\dot{\mathbf{M}}_{\text {air }_{21}} & \dot{\mathbf{M}}_{\text {air }_{22}}
\end{array}\right]\left[\begin{array}{c}
\ddot{F R}_{\ddot{\alpha}_{\mathrm{I}}}
\end{array}\right] } \\
&+\left[\begin{array}{l}
\mathbf{P}_{\text {motor }} \\
\mathbf{P}_{\text {motor } 2}
\end{array}\right]\left[\begin{array}{ll}
\dot{F} \dot{\alpha}_{\mathrm{I}}
\end{array}\right] \\
&+\left[\begin{array}{ll}
\mathbf{N}_{11} & \mathbf{N}_{12} \\
\mathbf{N}_{21} & \mathbf{N}_{22}
\end{array}\right] \times\left[\begin{array}{c}
\mathbf{F R} \\
\dot{\alpha_{I}}
\end{array}\right]^{2} \\
&+\left[\begin{array}{l}
\mathbf{M}_{\mathrm{a}_{1}} \\
\mathbf{M}_{\mathrm{a}_{2}}
\end{array}\right]
\end{aligned}
$$

Where $P F I$ is port fuel injector, $D I$ is direct injector, $\dot{\mathbf{M}}_{\text {air }}$ is a symmetric and positive define mass of air matrix, $\mathbf{P}_{\text {motor }}$ is the pressure of motor, $N$ is engine angular speed and $\mathbf{M}_{\mathbf{a}}$ is matrix mass of air in cylinder. Fuel ratio and exhaust angle are calculated by $[25,29$, 43-44]:

$$
\begin{aligned}
& {\left[\begin{array}{c}
F \ddot{R}_{a} \\
\ddot{\alpha}_{I_{a}}
\end{array}\right]=\left[\begin{array}{ll}
\dot{M}_{\text {air } 11_{11}} & \dot{M}_{\text {air }_{12}} \\
\dot{M}_{\text {air } 21} & \dot{M}_{\text {air } 22_{22}}
\end{array}\right]^{-1}\left\{\left[\begin{array}{c}
P F I \\
D I
\end{array}\right]\right.} \\
&-\left\{\left[\begin{array}{l}
P_{\text {motor }_{1}} \\
P_{\text {motor }_{2}}
\end{array}\right]\left[\begin{array}{ll}
F R & \dot{\alpha}_{I_{a}}
\end{array}\right]\right. \\
&+\left[\begin{array}{ll}
N_{11} & N_{12} \\
N_{21} & N_{22}
\end{array}\right] \\
&\left.\times\left[\begin{array}{c}
F \dot{R}_{a} \\
\dot{\alpha}_{I_{a}}
\end{array}\right]^{2}+\left[\begin{array}{c}
M_{a_{1}} \\
M_{a_{2}}
\end{array}\right]\right\}
\end{aligned}
$$

The above target equivalence ratio calculation will be combined with fuel ratio calculation that will be used for controller design purpose.

\subsection{Variable Structure Controller}

Consider a nonlinear single input dynamic system is defined by [11]:

$$
x^{(n)}=f(\vec{x})+b(\vec{x}) u
$$

Where $\mathrm{u}$ is the vector of control input, $\boldsymbol{x}^{(\boldsymbol{n})}$ is the $\boldsymbol{n}^{\text {th }}$ derivation of $x, x=\left[x, \dot{x}, \ddot{x}, \ldots, x^{(n-1)}\right]^{T}$ is the state vector, $\boldsymbol{f}(\boldsymbol{x})$ is unknown or uncertainty, and $\boldsymbol{b}(\boldsymbol{x})$ is of known sign function. The main goal to design this controller is train to the desired state; $\boldsymbol{x}_{\boldsymbol{d}}=$ $\left[x_{d}, \dot{x}_{d}, \ddot{x}_{d}, \ldots, x_{d}^{(n-1)}\right]^{T}$, and trucking error vector is defined by [16]:

$$
\widetilde{x}=x-x_{d}=\left[\widetilde{x}, \ldots, \widetilde{x}^{(n-1)}\right]^{T}
$$

A time-varying variable structure (VS) surface $\boldsymbol{s}(\boldsymbol{x}, \boldsymbol{t})$ in the state space $\boldsymbol{R}^{\boldsymbol{n}}$ is given by [22]:

$$
s(x, t)=\left(\frac{d}{d t}+\lambda\right)^{n-1} \tilde{x}=0
$$

where $\lambda$ is the positive constant and calculate it is play important role to have the best performance. The 
main target in this methodology is kept the VS surface slope $\boldsymbol{s}(\boldsymbol{x}, \boldsymbol{t})$ near to the zero. Therefore, one of the common strategies is to find input $\boldsymbol{U}$ outside of $\boldsymbol{s}(\boldsymbol{x}, \boldsymbol{t})[28]$.

$$
\frac{1}{2} \frac{d}{d t} s^{2}(x, t) \leq-\zeta|s(x, t)|
$$

where $\zeta$ is positive constant.

$$
\text { If } \mathbf{S}(\mathbf{0})>\mathbf{0} \rightarrow \frac{\mathrm{d}}{\mathrm{dt}} \mathbf{S}(\mathrm{t}) \leq-\zeta
$$

To eliminate the derivative term, it is used an integral term from $\mathrm{t}=0$ to $\mathrm{t}=\boldsymbol{t}_{\text {reach }}$

$$
\begin{aligned}
\int_{t=0}^{t=t_{\text {reach }}} \frac{d}{d t} S(t) & \leq-\int_{t=0}^{t=t_{\text {reach }}} \eta \\
& \rightarrow S\left(t_{\text {reach }}\right)-S(0) \\
& \leq-\zeta\left(t_{\text {reach }}-0\right)
\end{aligned}
$$

Where $t_{\text {reach }}$ is the time that trajectories reach to the VS surface so, suppose $\mathrm{S}\left(t_{\text {reach }}=0\right)$ defined as;

$$
0-S(0) \leq-\eta\left(t_{\text {reach }}\right) \rightarrow t_{\text {reach }} \leq \frac{S(0)}{\zeta}
$$

and

$$
\text { if } \begin{aligned}
\boldsymbol{S}(\mathbf{0})<0 \rightarrow 0 & -S(\mathbf{0}) \leq-\boldsymbol{\eta}\left(\boldsymbol{t}_{\text {reach }}\right) \\
& \rightarrow \boldsymbol{S}(\mathbf{0}) \leq-\zeta\left(\boldsymbol{t}_{\text {reach }}\right) \\
& \rightarrow \boldsymbol{t}_{\text {reach }} \leq \frac{|\boldsymbol{S}(\mathbf{0})|}{\boldsymbol{\eta}}
\end{aligned}
$$

Equation (11) guarantees time to reach the VS surface is smaller than $\frac{|\boldsymbol{S}(\mathbf{0})|}{\zeta}$ since the trajectories are outside of $S(t)$.

$$
\text { if } S_{t_{\text {reach }}}=S(0) \rightarrow \operatorname{error}\left(x-x_{d}\right)=0
$$

suppose $\mathrm{S}$ is defined as

$$
\begin{aligned}
s(x, t)=\left(\frac{d}{d t}+\lambda\right) & \tilde{x} \\
= & \left(\dot{\mathbf{x}}-\dot{\mathbf{x}}_{\mathbf{d}}\right) \\
& +\lambda\left(\mathbf{x}-\mathbf{x}_{\mathbf{d}}\right)
\end{aligned}
$$

The derivation of $\mathrm{S}$, namely, $\dot{S}$ can be calculated as the following;

$$
\dot{S}=\left(\ddot{\mathbf{x}}-\ddot{\mathbf{x}}_{\mathbf{d}}\right)+\lambda\left(\dot{\mathbf{x}}-\dot{\mathbf{x}}_{\mathbf{d}}\right)
$$

suppose the second order system is defined as;

$$
\begin{array}{r}
\ddot{x}=f+u \rightarrow \dot{S}=f+U-\ddot{x}_{d} \\
+\lambda\left(\dot{\mathbf{x}}-\dot{\mathbf{x}}_{\mathbf{d}}\right)
\end{array}
$$

Where $\boldsymbol{f}$ is the dynamic uncertain, and also since $S=0$ and $\dot{S}=0$, to have the best approximation,$\widehat{\boldsymbol{U}}$ is defined as

$$
\widehat{U}=-\widehat{f}+\ddot{x}_{d}-\lambda\left(\dot{\mathbf{x}}-\dot{\mathbf{x}}_{\mathbf{d}}\right)
$$

A simple solution to get the VS condition when the dynamic parameters have uncertainty is the switching control law [21-55]:

$$
U_{d i s}=\widehat{U}-K(\vec{x}, t) \cdot \operatorname{sgn}(s)
$$

where the switching function $\operatorname{sgn}(\mathbf{S})$ is defined as $[11,16]$

$$
\operatorname{sgn}(s)= \begin{cases}1 & s>0 \\ -1 & s<0 \\ 0 & s=0\end{cases}
$$

and the $\boldsymbol{K}(\overrightarrow{\boldsymbol{x}}, \boldsymbol{t})$ is the positive constant. Suppose by (7) the following equation can be written as,

$$
\begin{aligned}
\frac{1}{2} \frac{d}{d t} s^{2}(x, t)=\dot{S} & \cdot S \\
= & {[f-\widehat{f}-K \operatorname{sgn}(s)] } \\
\cdot S & =(f-\hat{f}) \cdot S-K|S|
\end{aligned}
$$

and if the equation (11) instead of (10) the VS surface can be calculated as

$$
\begin{aligned}
s(x, t)=\left(\frac{d}{d t}+\lambda\right)^{2} & \left(\int_{0}^{t} \tilde{x} d t\right) \\
& =\left(\dot{\mathbf{x}}-\dot{\mathbf{x}}_{\mathrm{d}}\right) \\
& +2 \lambda\left(\dot{\mathbf{x}}-\dot{\mathbf{x}}_{\mathrm{d}}\right) \\
& -\lambda^{2}\left(\mathbf{x}-\mathbf{x}_{\mathrm{d}}\right)
\end{aligned}
$$

in this method the approximation of $\boldsymbol{U}$ is computed as [26]

$$
\begin{aligned}
\widehat{U}=-\widehat{f}+\ddot{x}_{d}-2 & \lambda\left(\dot{\mathbf{x}}-\dot{\mathbf{x}}_{\mathbf{d}}\right) \\
& +\lambda^{2}\left(\mathbf{x}-\mathbf{x}_{\mathbf{d}}\right)
\end{aligned}
$$

Based on above discussion, the variable structure control law for IC engine is written as $[11,36]$ :

$$
P F I=P F I_{\text {model }}+P F I_{\text {error }}
$$

Where, the model-based component $\boldsymbol{P F} \boldsymbol{I}_{\text {model }}$ is the nominal dynamics of systems calculated as follows [18]: 


$$
\begin{aligned}
P F I_{\text {model }}=\left[\begin{array}{rl}
\dot{M}^{-1} & \text { air } \\
& \left(\left[\begin{array}{l}
P_{\text {motor }_{1}} \\
P_{\text {motor }}
\end{array}\right]\left[\begin{array}{cc}
F R & \dot{\alpha}_{I}
\end{array}\right]\right. \\
& +\left[\begin{array}{ll}
N_{11} & N_{12} \\
N_{21} & N_{22}
\end{array}\right] \times\left[\begin{array}{c}
F R \\
\dot{\alpha}_{I}
\end{array}\right]^{2} \\
& \left.+\left[\begin{array}{l}
M_{a_{1}} \\
M_{a_{2}}
\end{array}\right]\right)+\dot{S}
\end{array}\right] \dot{M}_{\text {air }}
\end{aligned}
$$

and $\boldsymbol{P} \boldsymbol{F} \boldsymbol{I}_{\text {error }}$ is computed as [25];

$$
P F I_{\text {error }}=K \cdot \operatorname{sgn}(S)
$$

By (24) and (23) the VSC of IC engine is calculated as;

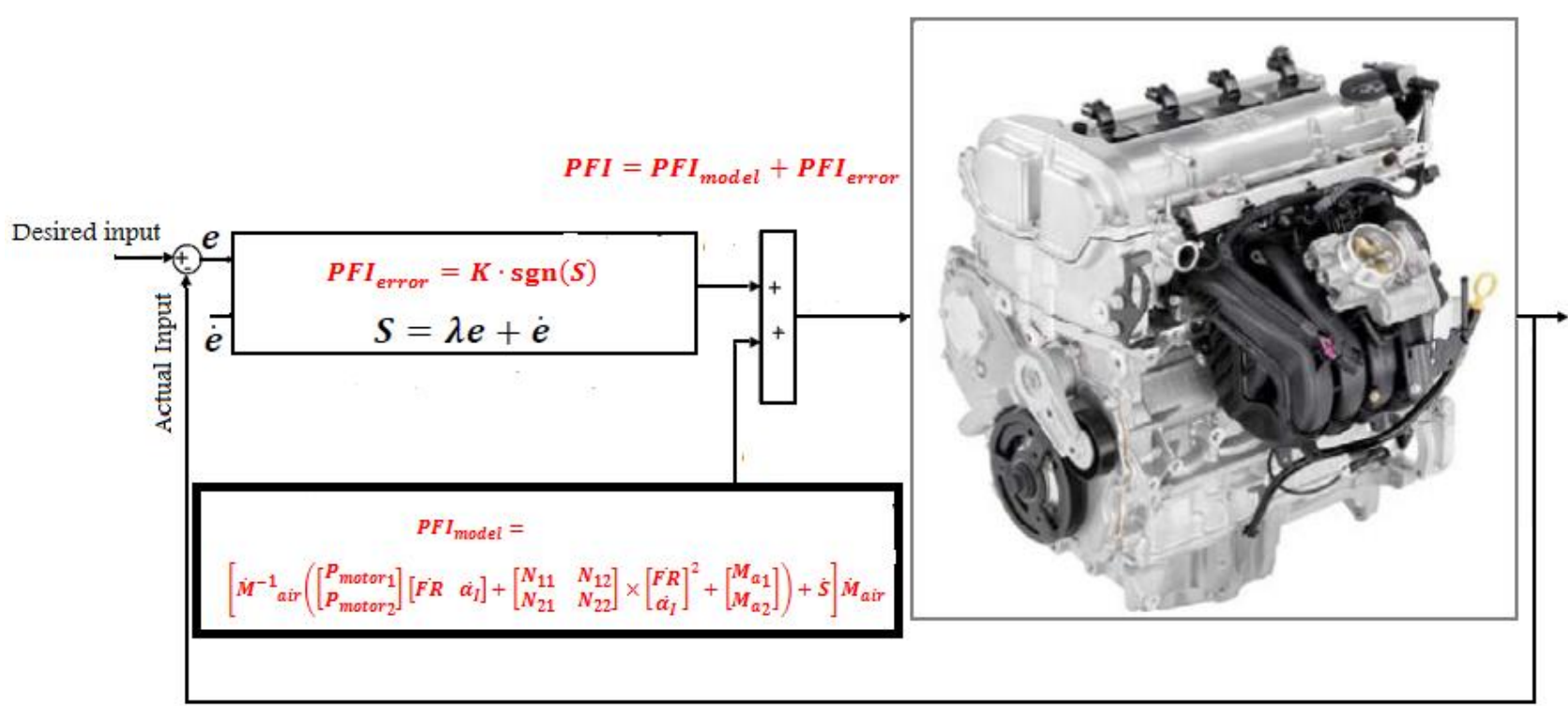

Fig. 1: Variable structure control of IC engine

\subsection{Baseline Methodology}

The design of a baseline methodology to control the fuel ratio was very straight forward. Since there was an output from the fuel ratio model, this means that there would be two inputs into the baseline controller. Similarly, the output of the controller result from the two control inputs of the port fuel injector signal and direct injector signal. In a typical PID method, the controller corrects the error between the desired input value and the measured value. Since the equivalence ratio and fuel ratio are the two measured signals, two controllers were cascaded together to control the PFI and DI inputs [14-18]. The first was a PID controller that corrected the error between the desired equivalence ratio and the measured equivalence ratio; while the second was only a proportional integral (PI) controller that corrected the fuel ratio error.

$$
\begin{array}{r}
e_{1}(t)=\alpha_{\text {target }}(t)-\alpha_{d}(t) \\
e_{2}(t)=\text { Fuel ratio }(t) \\
- \text { Fuel Ratio }_{d}(t)
\end{array}
$$

$$
\begin{aligned}
\tau=\left[\dot { M } ^ { - 1 } { } _ { \text { air } } \left(\left[\begin{array}{l}
P_{\text {motor }_{1}} \\
P_{\text {motor }}
\end{array}\right]\left[\begin{array}{ll}
\dot{F R} & \dot{\alpha}_{I}
\end{array}\right]\right.\right. \\
+\left[\begin{array}{ll}
N_{11} & N_{12} \\
N_{21} & N_{22}
\end{array}\right] \times\left[\begin{array}{c}
\dot{F R} \\
\dot{\alpha}_{I}
\end{array}\right]^{2} \\
\left.+\left[\begin{array}{l}
M_{a_{1}} \\
M_{a_{2}}
\end{array}\right]\right)+\dot{S} \\
+\dot{M}_{\text {air }} \\
+K \cdot \operatorname{sgn}(S)
\end{aligned}
$$

where $S=\lambda e+\dot{e}$

Figure 1 is shown pure VSC. 


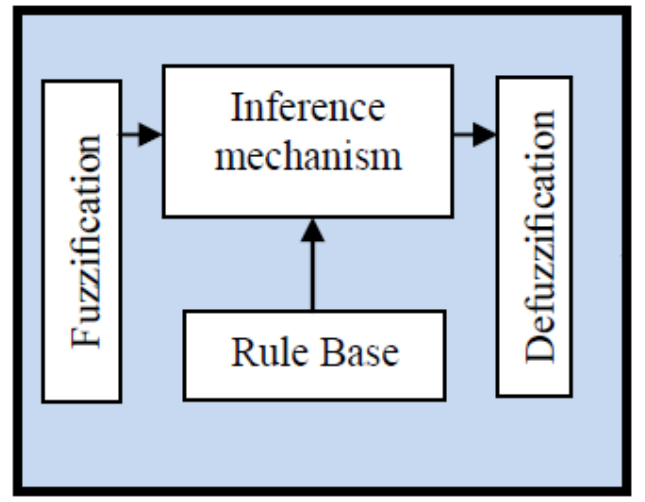

Fig. 2: Fuzzy Controller Part

The fuzzy inference engine offers a mechanism for transferring the rule base in fuzzy set which it is divided into two most important methods, namely, Mamdani method and Sugeno method. Mamdani method is one of the common fuzzy inference systems and he designed one of the first fuzzy controllers to control of system engine. Mamdani's fuzzy inference system is divided into four major steps: fuzzification, rule evaluation, aggregation of the rule outputs and defuzzification. Michio Sugeno use a singleton as a membership function of the rule consequent part. The following definition shows the Mamdani and Sugeno fuzzy rule base

\section{if $x$ is $A$ and $y$ is $B$ then $z$ is $C^{\prime}$ mamdani' if $x$ is $A$ and $y$ is $B$ then $z$ is $f(x, y)^{\prime}$ sugeno'}

When $x$ and $y$ have crisp values fuzzification calculates the membership degrees for antecedent part. Rule evaluation focuses on fuzzy operation $(A N D / O R)$ in the antecedent of the fuzzy rules. The aggregation is used to calculate the output fuzzy set and several methodologies can be used in fuzzy logic controller aggregation, namely, Max-Min aggregation, Sum-Min aggregation, Max-bounded product, Max-drastic product, Max-bounded sum, Max-algebraic sum and Min-max. Two most common methods that used in fuzzy logic controllers are Max-min aggregation and Sum-min aggregation. Max-min aggregation defined as below;

$$
\begin{aligned}
& \mu_{U}\left(x_{k}, y_{k}, U\right)=\mu_{\cup_{i=1}^{r} F R^{i}}\left(x_{k}, y_{k}, U\right) \\
& =\max \left\{\min _{i=1}^{r}\left[\mu_{R_{p q}}\left(x_{k}, y_{k}\right), \mu_{p_{m}}(U)\right]\right\}
\end{aligned}
$$

The Sum-min aggregation defined as below

$$
\begin{aligned}
& \mu_{U}\left(x_{k}, y_{k}, U\right)=\mu_{\cup_{i=1}^{r} F R^{i}}\left(x_{k}, y_{k}, U\right) \\
& =\sum \min _{i=1}^{r}\left[\mu_{R}\left(x_{k}, y_{k}\right), \mu_{p_{m}}(U)\right]
\end{aligned}
$$

where $r$ is the number of fuzzy rules activated by $x_{k}$ and $y_{k}$ and also $\mu_{\cup_{i=1}^{r} F R^{i}}\left(x_{k}, y_{k}, U\right)$ is a fuzzy interpretation of $i-t h$ rule. Defuzzification is the last step in the fuzzy inference system which it is used to transform fuzzy set to crisp set. Consequently defuzzification's input is the aggregate output and the defuzzification's output is a crisp number. Centre of gravity method (COG) and Centre of area method (COA) are two most common defuzzification methods, which $C O G$ method used the following equation to calculate the defuzzification

$$
\operatorname{COG}\left(x_{k}, y_{k}\right)=\frac{\sum_{i} U_{i} \sum_{j=1}^{r} \cdot \mu_{u}\left(x_{k}, y_{k}, U_{i}\right)}{\sum_{i} \sum_{j=1}^{r} \cdot \mu_{u}\left(x_{k}, y_{k}, U_{i}\right)}
$$

and $C O A$ method used the following equation to calculate the defuzzification

$$
\operatorname{COA}\left(x_{k}, y_{k}\right)=\frac{\sum_{i} U_{i} \cdot \mu_{u}\left(x_{k}, y_{k}, U_{i}\right)}{\sum_{i} \mu_{U} \cdot\left(x_{k}, y_{k}, U_{i}\right)}
$$

Where $\operatorname{COG}\left(x_{k}, y_{k}\right)$ and $\operatorname{COA}\left(x_{k}, y_{k}\right)$ illustrates the crisp value of defuzzification output, $U_{i} \in U$ is discrete element of an output of the fuzzy set, $\mu_{U} \cdot\left(x_{k}, y_{k}, U_{i}\right)$ is the fuzzy set membership function, and $r$ is the number of fuzzy rules.

\section{Methodology}

\subsection{Design Fuzzy Baseline Variable Structure Controller}

As shown in Figure 1, variable structure controller has two main parts: error-based part and model-based part. Error-based part is based on performance based switching function to have stability, but it can caused to system's chattering. Model-based part is based on IC engine's dynamic formulation, based on nonlinear; MIMO and uncertain dynamic formulation. To have an IC engine's dynamic independent methodology, fuzzy logic theory is applied to VSC. Based on literature [4344 , 58-61], most of researchers are designed fuzzy model-based VSC. In this method fuzzy logic method is used to estimate some unknown dynamic formulation. Above methods have acceptable performance based on dynamic modeling of IC engines but this research is focused on eliminate the nonlinear IC engine's dynamic formulation. In this method; nonlinear dynamic model based part is replaced by performance/error-based Mamdani's fuzzy inference system. It has considered one input; variable structure surface $(S)$, one output; $P F I / D I$ and totally 7 rules instead of the nonlinear dynamic model part. Figure 3 is shown Mamdani's fuzzy inference variable structure methodology. This method has an important challenge to adjust the variable structure slope $(\lambda)$. To solve above challenge new based-line method is applied to fuzzy variable structure methodology to reduce the role of initial value of $\lambda$ in fuzzy variable structure methodology. 


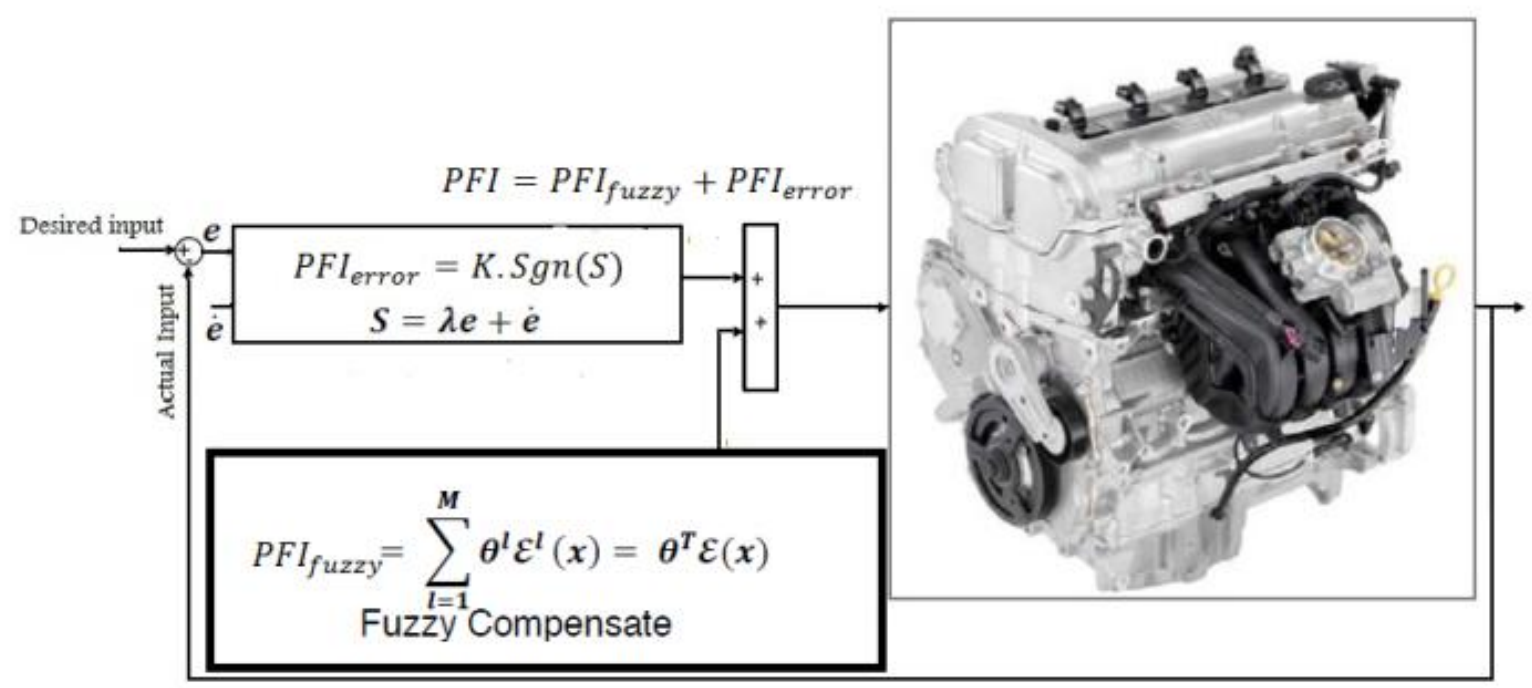

Fig. 3: Mamdani’s Fuzzy Inference Variable Structure Controller

In fuzzy VSC the PD-variable structure surface is defined as follows:

$$
S=\dot{e}+\lambda \boldsymbol{e}
$$

where $\lambda_{1}=\operatorname{diag}\left[\lambda_{11}, \lambda_{12}, \lambda_{13}\right]$. The time derivative of $\mathrm{S}$ is computed;

$$
\dot{\boldsymbol{S}}=\ddot{\boldsymbol{q}}_{d}+\lambda \dot{\boldsymbol{e}}
$$

Based on Figure 3, the fuzzy variable structure controller's output is written;

$$
\widehat{P F I}=P F I_{\text {fuzzy }}+P F I_{\text {error }}
$$

Based on fuzzy logic methodology

$$
f(x)=U_{\text {fuzzy }}=\sum_{l=1}^{M} \theta^{T} \zeta(x)
$$

where $\boldsymbol{\theta}^{\boldsymbol{T}}$ is adjustable parameter (gain updating factor) and $\boldsymbol{\zeta}(\boldsymbol{x})$ is defined by

$$
\zeta(x)=\frac{\sum_{i} \mu\left(x_{i}\right) x_{i}}{\sum_{i} \mu\left(x_{i}\right)}
$$

Where $\boldsymbol{\mu}\left(\boldsymbol{x}_{\boldsymbol{i}}\right)$ is membership function. $\boldsymbol{P F} \boldsymbol{I}_{\boldsymbol{f u z z} \boldsymbol{y}}$ is defined as follows;

$$
\begin{aligned}
& P F I_{f u z z y}=\sum_{l=1}^{M} \theta^{T} \zeta(x)= \\
& {\left[\dot { M } ^ { - 1 } { } _ { \text { air } } \left(\left[\begin{array}{l}
P_{\text {motor }_{1}} \\
P_{\text {motor }_{2}}
\end{array}\right]\left[\begin{array}{ll}
\dot{F R} & \dot{\alpha}_{I}
\end{array}\right]+\right.\right.} \\
& \left.\left[\begin{array}{ll}
N_{11} & N_{12} \\
N_{21} & N_{22}
\end{array}\right] \times\left[\begin{array}{c}
F R \\
\dot{\alpha}_{I}
\end{array}\right]^{2}+\left[\begin{array}{c}
M_{a_{1}} \\
M_{a_{2}}
\end{array}\right]\right)+ \\
& \dot{S}] \dot{M}_{\text {air }}
\end{aligned}
$$

Design fuzzy like nonlinear equivalent part has the following steps;

Fuzzification: in this step the researcher must to defined the linguistic variables for input, $(S)$, and outputs, (PFI and DI) . This research defined 7 linguistic variables for input and output which names; Negative Big (NB), Negative Medium (NM), Negative Small (NS), Zero (ZE), Positive Small (PS), Positive Medium (PM) and Positive Big (PB). Triangular membership function is used to design this controller. Based on this membership function it can guarantee the output performance. Input and output are quantized into thirteen levels represented by: $-6,-5,-0.4,-3,-2,-1,0,1$, $2,3,4,5,6$.

Fuzzy rule base and rule evaluation: this design has 7 rules which design by researcher's experience knowledge. Design the rule base of fuzzy inference system can play important role to design the best performance of fuzzy VSC, that to calculate the fuzzy rule base the researcher is used to heuristic method which, it is based on the behavior of the control of IC engine. Table 1 is shown the fuzzy rule table in fuzzy VSC.

Table 1: Modified Fuzzy Variable Structure Rule Table

\begin{tabular}{|c|c|c|c|c|c|c|c|}
\hline$S$ & NB & NM & NS & ZE & PS & PM & PB \\
\hline$P F I_{\text {fuzzy }}$ & PB & PM & PS & ZE & NS & NM & NB \\
\hline
\end{tabular}

Rule evaluation focuses on operation in the antecedent of the fuzzy rules in fuzzy variable structure controller. In this research, researcher is used $A N D$ fuzzy operation in antecedent part. After calculate rule evaluation, activation degree applied to antecedent part and connect it to consequent part based on AND operation in antecedent part. Finally rule aggregation is 
introduced which, Max-Min aggregation is used in this paper.

Inference Mechanism: in this paper Mamdani's fuzzy inference mechanism is used based on eliminate the IC engine's dynamic formulation.

Defuzzification: the final steps to design fuzzy VS controller is select the defuzzification methodology. In this paper Center of Gravity method (COG) is used to transform fuzzy to crisp.

\subsection{PID Baseline PFI Fuzzy Variable Structure Controller and Optimization by Gradient Decsent Method}

The most important coefficient in fuzzy variable structure methodology is, variable surface slope. Predefined this coefficient is complicated; therefore this research is used PID baseline method and applied to fuzzy logic methodology. PID baseline methodology is tune based on three coefficient; namely $\boldsymbol{K}_{p}, \boldsymbol{K}_{v}, \boldsymbol{K}_{\boldsymbol{i}}$. One of the positive effects of these three coefficients is tune the PFI easily. Figure 4 is shown the proposed method.

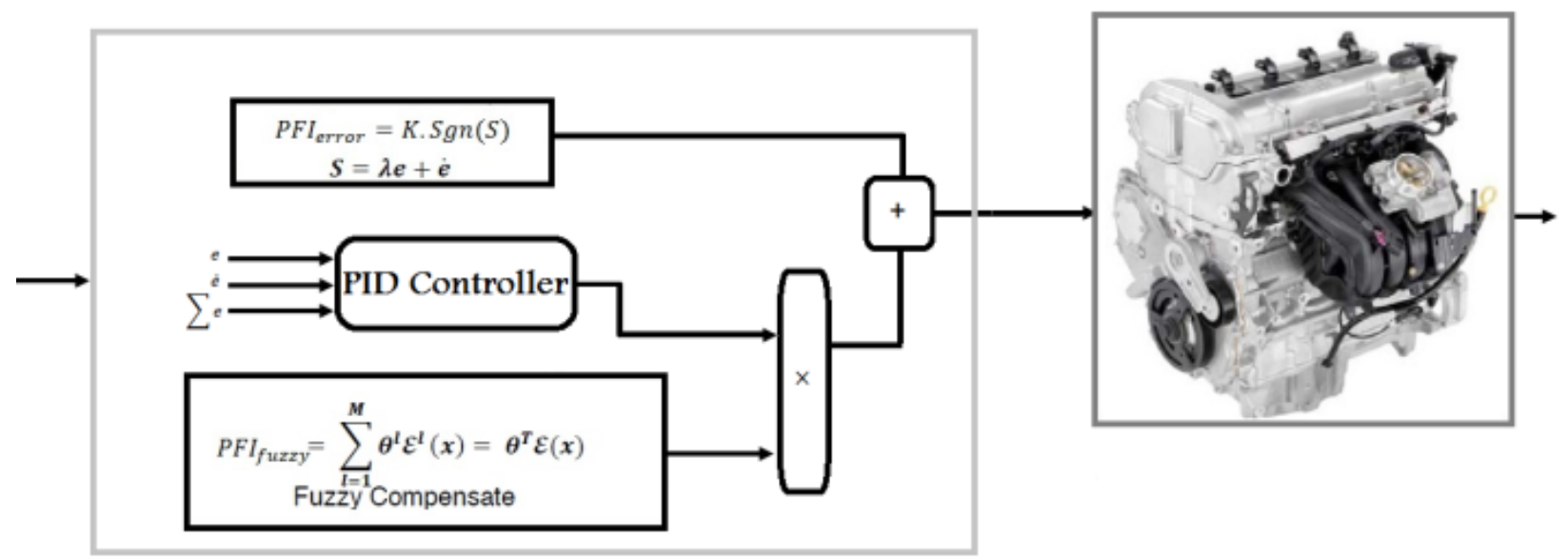

Fig. 4: Baseline Mamdani's Fuzzy Inference Variable Structure Controller

Pure variable structure controller and fuzzy variable structure controller are tuned based on variable structure surface slope $(\lambda)$ that tune it to have best performance is very complicated. For instance, if large value of $\lambda$ is chosen the response is very fast the system is unstable and conversely, if small value of $\boldsymbol{\lambda}$ is considered the response of system is very slow but system is stable. Therefore to have a good response, compute the best value variable structure slope coefficient is very important. To adjust this coefficient Gradient Descent optimization is introduced which this method is worked based on the observation methodology. To easy tuning PID baseline methodology is used. When this method is applied to fuzzy variable structure methodology the number of coefficient are increases but tune them are better than previous.

\section{Results and Discussion}

Gradient Descent Fuzzy Baseline Variable Structure Controller (GDFBVSC) and Fuzzy Variable Structure Controller (FVSC) was tune the fuel to air ratio. In this simulation, to adjust the fuel to air ratio variable torque load also is applied. The simulation was implemented in MATLAB/SIMULINK environment.
Optimization the fuzzy baseline VSC: in GDFBVSC; controller's performance are depending on the PID coefficient $K_{p}, K_{v}, K_{i}$ and variable structure slope coefficient $(\lambda)$. These four coefficients are computed by Gradient Descent Algorithm optimization; Figure 5 and Figure 6.

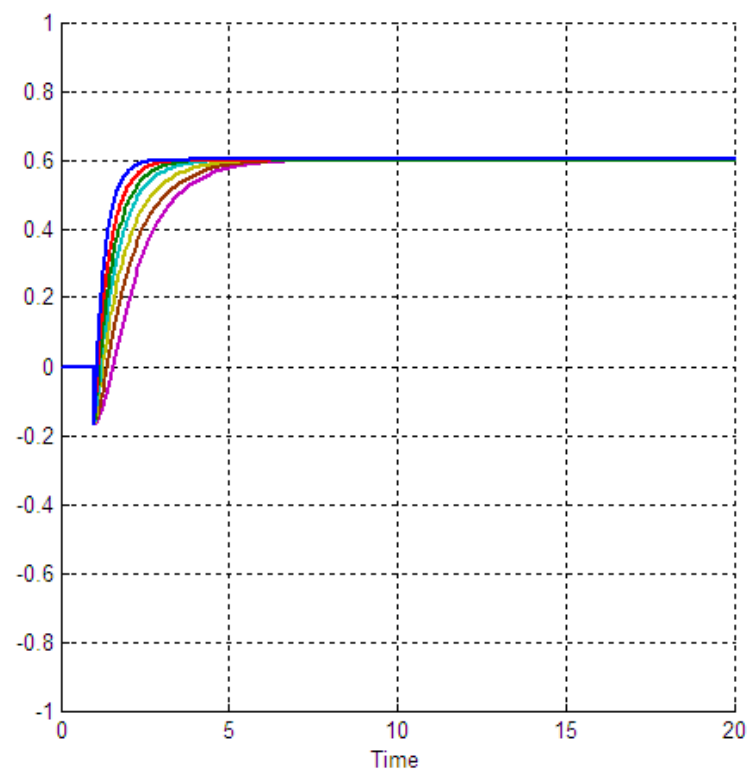

Fig. 5: Fuel Ratio Gradient descent optimization in fuzzy baseline variable structure methodology 
Fuel ratio in fixed torque load: In fuzzy variable structure methodology; the fuel ratio is only depended on the gain updating factor $(K)$ and variable structure slope coefficient $(\lambda)$. In fuzzy baseline variable structure method PID coefficients and coefficients which is introduced in fuzzy variable structure method are used. These coefficients are computed by gradient descent optimization. Figure 7 shows fuel ratio in these two methodologies when the torque load is fixed.

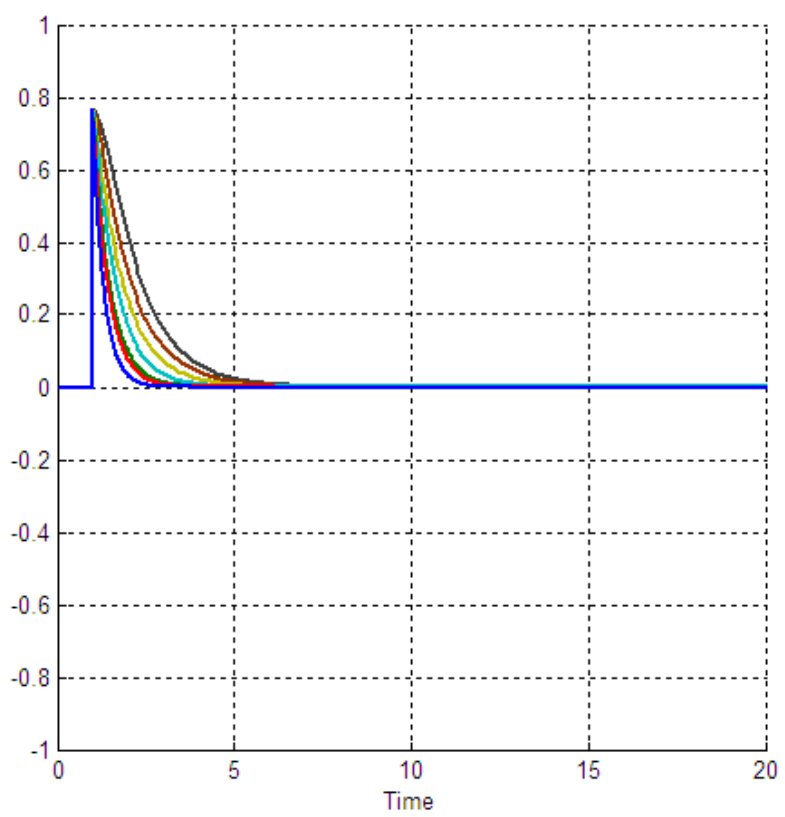

Fig. 6: Error's Fuel Ratio Gradient descent fuzzy baseline variable structure methodology

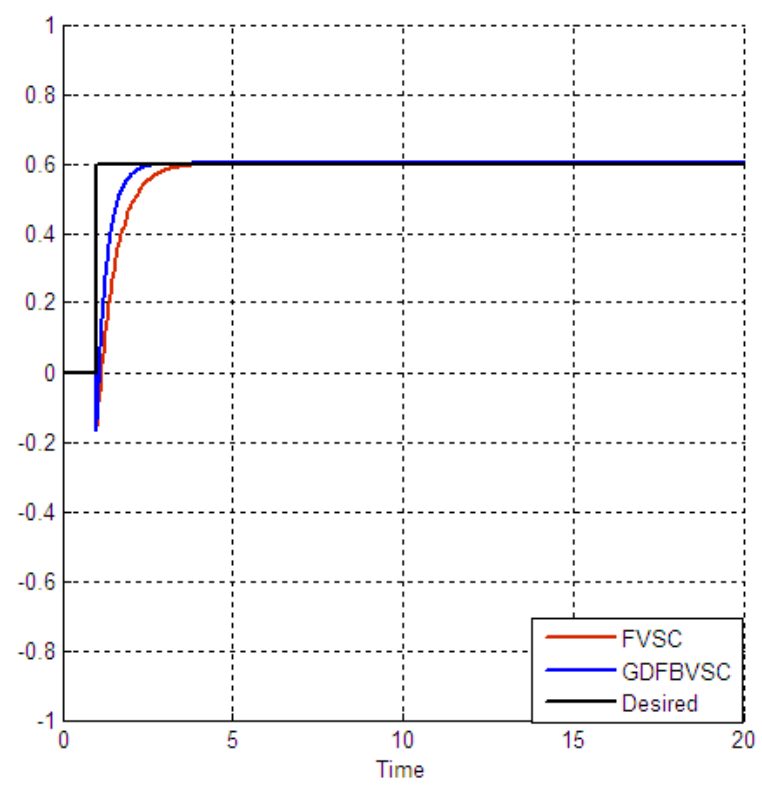

Fig. 7: Fuel ratio in Fuzzy variable structure method Vs. Gradient descent fuzzy baseline variable structure method

It may be claimed that however the first method is used in our previous research but proposed method has a better performance in this system when the torque load is fixed. The data indicates that proposed method can guarantee the stability and minimal error.

Torque Load Rejection and adjust the Fuel Ratio: Figure 8 is shown the power torque load elimination in fuzzy variable structure method and gradient descent optimal fuzzy baseline variable structure methodology with variable torque load. As a matter of fact the torque load rejection is used to test the robustness of these two methods. Surely after applied different torque load it found fairly fluctuations in fuel ratio responses. Actually one of the main advantages of baseline method is stability in fuel ratio in presence of different torque load. A further advantage of proposed method is robustness compared to fuzzy variable structure method.

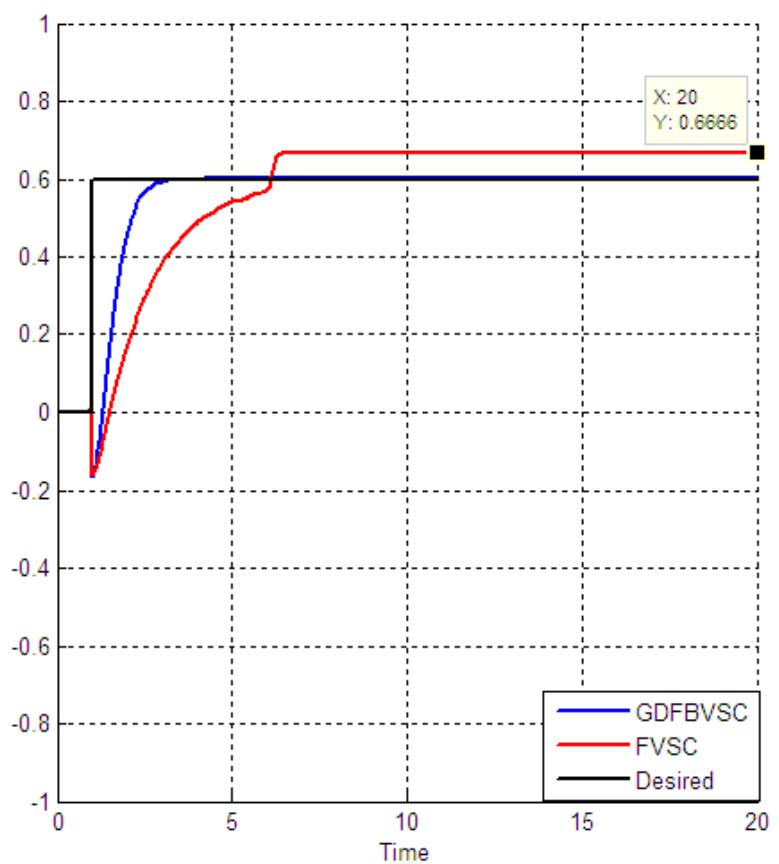

Fig. 8: Torque load rejection in Fuzzy variable structure method Vs. Gradient descent fuzzy baseline variable structure method

Based on Figure 8, overall when baseline method applied to fuzzy variable structure methodology it can eliminate the limited external disturbance (torque load).

\section{Conclusion}

Refer to this research, design an artificial intelligence based nonlinear methodology is proposed to tune the fuel ratio in IC engine. At first pure variable structure methodology is design for IC engine. This method has two important challenge; chattering phenomenon and nonlinear equivalent dynamic part. In the second part Mamdani's fuzzy inference system is applied to variable structure method to solve above two challenges. To eliminate the IC engine system's dynamic, 7 rules Mamdani inference system is design and applied to variable structure methodology. This methodology is 
based on applied fuzzy logic in equivalent nonlinear dynamic part to estimate unknown parameters.Both of above controllers are depending on variable structure slope that to solve this challenge baseline methodology is applied to fuzzy variable structure method. Eventually gradient descent optimization is applied to fuzzy baseline methodology to tune all four parameters. The fuel ratio results demonstrate that the gradient descent fuzzy baseline variable structure methodology is a model-free methods which works well in certain and partly uncertain system.

\section{Acknowledgment}

The authors would like to thank the anonymous reviewers for their careful reading of this paper and for their helpful comments. This work was supported by the SSP Research and Development Corporation Program of Iran under grant no. 2012-Persian Gulf-2B.

\section{References}

[1] Heywood, J., "Internal Combustion Engine Fundamentals", McGraw-Hill, New York, 1988.

[2] J. G. Rivard, "Closed-loop Electronic Fuel Injection Control of the IC Engine," in Society of Automotive Engineers, 1973.

[3] J. F. Cassidy, et al, "On the Design of Electronic Automotive Engine Controls using linear Quadratic Control Theory," IEEE Trans on Control Systems, vol. AC-25, October 1980.

[4] W. E. Powers, "Applications of Optimal Control and Kalman Filtering to Automotive Systems," International Journal of Vehicle Design, vol. Applications of Control Theory in the Automotive Industry, 1983.

[5] N. F. Benninger, et al, "Requirements and Perfomance of Engine Management Systems under Transient Conditions," in Society of Automotive Engineers, 1991.

[6] N. F. Benninger, et al, "Requirements and Perfomance of Engine Management Systems under Transient Conditions," in Society of Automotive Engineers, 1991.

[7] C. H. Onder, et al, "Model-Based Multivariable Speed and Air-to-Fuel Ratio Control of an SI Engine," in Society of Automotive Engineers, 1993.

[8] S. B. Cho, et al, "An Observer-based Controller Design Method for Automotive Fuel-Injection Systems," in American Controls Conference, 1993, pp. 2567-2571.

[9] T. Kume, et al, "Combustion Technologies for Direct Injection SI Engine," in Society of Automotive Engineers, 1996.
[10] V. Utkin, "Variable structure systems with sliding modes," Automatic Control, IEEE Transactions on, No. 2, vol. 22, pp. 212-222, 2002.

[11] R. A. DeCarlo, S. H. Zak and G. P. Matthews, "Variable structure control of nonlinear multivariable systems: a tutorial," Proceedings of the IEEE, No. 3, vol. 76, pp. 212-232, 2002.

[12] K. D. Young, V. Utkin and U. Ozguner, "A control engineer's guide to sliding mode control," IEEE conference proceeding, 2002, pp. 1-14.

[13] O. Kaynak, "Guest editorial special section on computationally intelligent methodologies and sliding-mode control," IEEE Transactions on Industrial Electronics, No. 1, vol. 48, pp. 2-3, 2001.

[14] P. Kachroo and M. Tomizuka, "Chattering reduction and error convergence in the slidingmode control of a class of nonlinear systems," Automatic Control, IEEE Transactions on, No. 7, vol. 41, pp. 1063-1068, 2002.

[15] Farzin Piltan , M. A. Bairami, F. Aghayari, S. Allahdadi, "Design Adaptive Artificial Inverse Dynamic Controller: Design Sliding Mode Fuzzy Adaptive New Inverse Dynamic Fuzzy Controller," International Journal of Robotic and Automation, 3 (1): 13-26, 2012.

[16] J. Moura and N. Olgac, "A comparative study on simulations vs. experiments of SMCPE," IEEE conference proceeding, 2002, pp. 996-1000.

[17] Farzin Piltan , S. Allahdadi, M. A. Bairami, H. Nasiri, "Design Auto Adjust Sliding Surface Slope: Applied to Robot Manipulator," International Journal of Robotic and Automation, 3 (1): 27-44, 2012.

[18] Farzin Piltan , N. Sulaiman, Zahra Tajpaykar, Payman Ferdosali, Mehdi Rashidi, "Design Artificial Nonlinear Robust Controller Based on CTLC and FSMC with Tunable Gain," International Journal of Robotic and Automation, 2 (3): 205-220, 2011.

[19] Farzin Piltan, A. R. Salehi and Nasri B Sulaiman.," Design artificial robust control of second order system based on adaptive fuzzy gain scheduling," world applied science journal (WASJ), 13 (5): 1085-1092, 2011.

[20] Farzin Piltan, N. Sulaiman, Atefeh Gavahian, Samira Soltani, Samaneh Roosta, "Design Mathematical Tunable Gain PID-Like Sliding Mode Fuzzy Controller with Minimum Rule Base," International Journal of Robotic and Automation, 2 (3): 146-156, 2011.

[21] Farzin Piltan , A. Zare, Nasri B. Sulaiman, M. H. Marhaban and R. Ramli, , "A Model Free Robust Sliding Surface Slope Adjustment in Sliding Mode Control for Robot Manipulator," World Applied Science Journal, 12 (12): 2330-2336, 2011. 
[22] Farzin Piltan , A. H. Aryanfar, Nasri B. Sulaiman, M. H. Marhaban and R. Ramli "Design Adaptive Fuzzy Robust Controllers for Robot Manipulator," World Applied Science Journal, 12 (12): 23172329, 2011.

[23] Farzin Piltan, N. Sulaiman , Arash Zargari, Mohammad Keshavarz, Ali Badri , "Design PIDLike Fuzzy Controller With Minimum Rule Base and Mathematical Proposed On-line Tunable Gain: Applied to Robot Manipulator," International Journal of Artificial intelligence and expert system, 2 (4):184-195, 2011.

[24] Farzin Piltan, Nasri Sulaiman, M. H. Marhaban and R. Ramli, "Design On-Line Tunable Gain Artificial Nonlinear Controller," Journal of Advances In Computer Research, 2 (4): 75-83, 2011.

[25] Farzin Piltan, N. Sulaiman, Payman Ferdosali, Iraj Assadi Talooki, “ Design Model Free Fuzzy Sliding Mode Control: Applied to Internal Combustion Engine," International Journal of Engineering, 5 (4):302-312, 2011.

[26] Farzin Piltan, N. Sulaiman, Samaneh Roosta, M.H. Marhaban, R. Ramli, "Design a New Sliding Mode Adaptive Hybrid Fuzzy Controller," Journal of Advanced Science \& Engineering Research , 1 (1): 115-123, 2011.

[27] Farzin Piltan, Atefe Gavahian, N. Sulaiman, M.H. Marhaban, R. Ramli, "Novel Sliding Mode Controller for robot manipulator using FPGA," Journal of Advanced Science \& Engineering Research, 1 (1): 1-22, 2011.

[28] Farzin Piltan, N. Sulaiman, A. Jalali \& F. Danesh Narouei, "Design of Model Free Adaptive Fuzzy Computed Torque Controller: Applied to Nonlinear Second Order System," International Journal of Robotics and Automation, 2 (4):232-244 2011.

[29] Farzin Piltan, N. Sulaiman, Iraj Asadi Talooki, Payman Ferdosali, "Control of IC Engine: Design a Novel MIMO Fuzzy Backstepping Adaptive Based Fuzzy Estimator Variable Structure Control ," International Journal of Robotics and Automation, 2 (5):360-380, 2011.

[30] Farzin Piltan, N. Sulaiman, Payman Ferdosali, Mehdi Rashidi, Zahra Tajpeikar, “Adaptive MIMO Fuzzy Compensate Fuzzy Sliding Mode Algorithm: Applied to Second Order Nonlinear System," International Journal of Engineering, 5 (5): 380398, 2011.

[31] Farzin Piltan, N. Sulaiman, Hajar Nasiri, Sadeq Allahdadi, Mohammad A. Bairami, "Novel Robot Manipulator Adaptive Artificial Control: Design a Novel SISO Adaptive Fuzzy Sliding Algorithm Inverse Dynamic Like Method," International Journal of Engineering, 5 (5): 399-418, 2011.
[32] Farzin Piltan, N. Sulaiman, Sadeq Allahdadi, Mohammadali Dialame, Abbas Zare, "Position Control of Robot Manipulator: Design a Novel SISO Adaptive Sliding Mode Fuzzy PD Fuzzy Sliding Mode Control," International Journal of Artificial intelligence and Expert System, 2 (5):208-228, 2011.

[33] Farzin Piltan, SH. Tayebi HAGHIGHI, N. Sulaiman, Iman Nazari, Sobhan Siamak, "Artificial Control of PUMA Robot Manipulator: A-Review of Fuzzy Inference Engine And Application to Classical Controller ," International Journal of Robotics and Automation, 2 (5):401-425, 2011.

[34] Farzin Piltan, N. Sulaiman, Abbas Zare, Sadeq Allahdadi, Mohammadali Dialame, "Design Adaptive Fuzzy Inference Sliding Mode Algorithm Applied to Robot Arm," International Journal of Robotics and Automation , 2 (5): 283-297, 2011.

[35] Farzin Piltan, Amin Jalali, N. Sulaiman, Atefeh Gavahian, Sobhan Siamak, "Novel Artificial Control of Nonlinear Uncertain System: Design a Novel Modified PSO SISO Lyapunov Based Fuzzy Sliding Mode Algorithm ," International Journal of Robotics and Automation, 2 (5): 298316, 2011.

[36] Farzin Piltan, N. Sulaiman, Amin Jalali, Koorosh Aslansefat, "Evolutionary Design of Mathematical tunable FPGA Based MIMO Fuzzy Estimator Sliding Mode Based Lyapunov Algorithm: Applied to Robot Manipulator," International Journal of Robotics and Automation, 2 (5):317-343, 2011.

[37] Farzin Piltan, N. Sulaiman, Samaneh Roosta, Atefeh Gavahian, Samira Soltani, "Evolutionary Design of Backstepping Artificial Sliding Mode Based Position Algorithm: Applied to Robot Manipulator," International Journal of Engineering, 5 (5):419-434, 2011.

[38] Farzin Piltan, N. Sulaiman, S.Soltani, M. H. Marhaban \& R. Ramli, "An Adaptive sliding surface slope adjustment in PD Sliding Mode Fuzzy Control for Robot Manipulator," International Journal of Control and Automation , 4 (3): 65-76, 2011.

[39] Farzin Piltan, N. Sulaiman, Mehdi Rashidi, Zahra Tajpaikar, Payman Ferdosali, "Design and Implementation of Sliding Mode Algorithm: Applied to Robot Manipulator-A Review ," International Journal of Robotics and Automation, 2 (5):265-282, 2011

[40] Farzin Piltan, N. Sulaiman, Amin Jalali, Sobhan Siamak, and Iman Nazari, "Control of Robot Manipulator: Design a Novel Tuning MIMO Fuzzy Backstepping Adaptive Based Fuzzy Estimator Variable Structure Control ," 
International Journal of Control and Automation, 4 (4):91-110, 2011.

[41] Farzin Piltan, N. Sulaiman, Atefeh Gavahian, Samaneh Roosta, Samira Soltani, "On line Tuning Premise and Consequence FIS: Design Fuzzy Adaptive Fuzzy Sliding Mode Controller Based on Lyaponuv Theory," International Journal of Robotics and Automation, 2 (5):381-400, 2011.

[42] Farzin Piltan, N. Sulaiman, Samaneh Roosta, Atefeh Gavahian, Samira Soltani, "Artificial Chattering Free on-line Fuzzy Sliding Mode Algorithm for Uncertain System: Applied in Robot Manipulator," International Journal of Engineering, 5 (5):360-379, 2011.

[43] Farzin Piltan, N. Sulaiman and I.AsadiTalooki, "Evolutionary Design on-line Sliding Fuzzy Gain Scheduling Sliding Mode Algorithm: Applied to Internal Combustion Engine," International Journal of Engineering Science and Technology, 3 (10):7301-7308, 2011.

[44] Farzin Piltan, Nasri B Sulaiman, Iraj Asadi Talooki and Payman Ferdosali.," Designing On-Line Tunable Gain Fuzzy Sliding Mode Controller Using Sliding Mode Fuzzy Algorithm: Applied to Internal Combustion Engine," world applied science journal (WASJ), 15 (3): 422-428, 2011.

[45] Farzin Piltan, N. Sulaiman, M. H. Marhaban, Adel Nowzary, Mostafa Tohidian," "Design of FPGA based sliding mode controller for robot manipulator," International Journal of Robotic and Automation, 2 (3): 183-204, 2011.

[46] Farzin Piltan, S. Siamak, M. A Bairami, I. Nazari," Gradient Descent Optimal Chattering Free Sliding Mode Fuzzy Control Design: Lyapunov Approach," International Journal of Advance Science and Technology, 45: 73-90, 2012.

[47] Farzin Piltan, H. Rezaie, B. Boroomand, Arman Jahed," Design robust back stepping online tuning feedback linearization control applied to IC engine," International Journal of Advance Science and Technology, 42: 183-204, 2012.

[48] Farzin Piltan, I. Nazari, S. Siamak, P. Ferdosali ,'Methodology of FPGA-based mathematical error-based tuning sliding mode controller" International Journal of Control and Automation, 5(1): 89-110, 2012.

[49] Farzin Piltan, M. A. Dialame, A. Zare, A. Badri ,'Design Novel Lookup table changed Auto Tuning FSMC: Applied to Robot Manipulator" International Journal of Engineering, 6(1): 25-40, 2012.

[50] Farzin Piltan, B. Boroomand, A. Jahed, H. Rezaie ,"Methodology of Mathematical ErrorBased Tuning Sliding Mode Controller"
International Journal of Engineering, 6(2): 96-112, 2012.

[51] Farzin Piltan, F. Aghayari, M. R. Rashidian, M. Shamsodini, "A New Estimate Sliding Mode Fuzzy Controller for Robotic Manipulator" International Journal of Robotics and Automation, 3(1): 45-58, 2012.

[52] Piltan, F., et al. "Design sliding mode controller for robot manipulator with artificial tunable gain". Canaidian Journal of pure and applied science, 5 (2), 1573-1579, 2011.

[53] Farzin Piltan, A. Hosainpour, E. Mazlomian, M.Shamsodini, M.H Yarmahmoudi. "Online Tuning Chattering Free Sliding Mode Fuzzy Control Design: Lyapunov Approach" International Journal of Robotics and Automation, 3(3): 2012.

[54] Farzin Piltan, S. Emamzadeh, Z. Hivand, F. Shahriyari \& Mina Mirazaei ." PUMA-560 Robot Manipulator Position Sliding Mode Control Methods Using MATLAB/SIMULINK and Their Integration into Graduate/Undergraduate Nonlinear Control, Robotics and MATLAB Courses" International Journal of Robotics and Automation, 3(3): 2012.

[55] Farzin Piltan, J. Meigolinedjad, S. Mehrara, S. Rahmdel. " Evaluation Performance of $2^{\text {nd }}$ Order Nonlinear System: Baseline Control Tunable Gain Sliding Mode Methodology" International Journal of Robotics and Automation, 3(3): 2012.

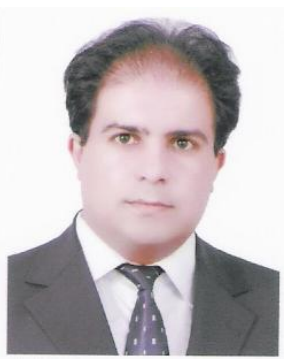

Farzin Piltan was born on 1975 , Shiraz, Iran. In 2004 he is jointed the research and development company, SSP Co, Shiraz, Iran. In addition to 7 textbooks, Farzin Piltan is the main author of more than 50 scientific papers in refereed journals. He is editorial board of international journal of control and automation (IJCA), editorial board of International Journal of Intelligent System and Applications (IJISA), editorial board of IAES international journal of robotics and automation, editorial board of International Journal of Reconfigurable and Embedded Systems and reviewer of (CSC) international journal of robotics and automation. His main areas of research interests are nonlinear control, artificial control system and applied to FPGA, robotics and artificial nonlinear control and IC engine modelling and control. 


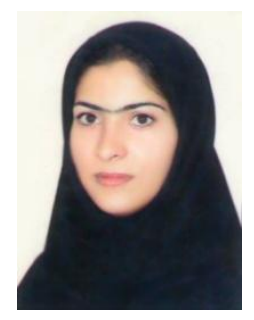

Mojdeh Piran is an industrial management researcher of research and development company SSP. Co. She is now pursuing her Master in industrial management. She is an expert Industrial and Quality Management in this company. Her research activities deal with the IC engine control, artificial intelligence and expert system.

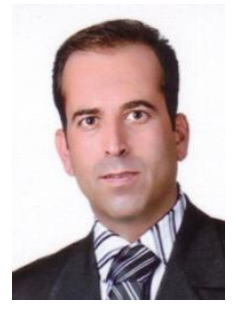

Mansour Bazregar is an industrial management researcher of research and development company SSP. Co. $\mathrm{He}$ is now pursuing his Master in industrial management. $\mathrm{He}$ is an expert Industrial and Quality Management in this company. His research activities deal with the IC engine control and supply chain management.

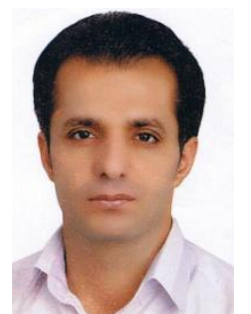

Mehdi Akbari is an industrial management researcher of research and development company SSP. Co. $\mathrm{He}$ is now pursuing his Master in industrial management. $\mathrm{He}$ is an expert Industrial and Quality Management in this company. His research activities deal with the IC engine control, artificial intelligence and supply chain management. 